\title{
PENGARUH PENGETAHUAN PERATURAN PAJAK DAN PERSEPSI EFEKTIVITAS SISTEM PERPAJAKAN TERHADAP KEPATUHAN WAJIB PAJAK (STUDI KASUS PADA FENOMENA SELEBGRAM KOTA PALEMBANG)
}

\author{
Muhammad Reza Pratama \\ Hadli, SE.,M.Si \\ Ikraam, SE., M.Si.
}

\begin{abstract}
This study aims to re-examine the effect of knowledge of tax regulations and perceptions of the effectiveness of the taxation system on several celebrities in the city of Palembang. The data used in this study are primary data obtained from questionnaires distributed to respondents. The data that have been collected are 31 questionnaires from 31 questionnaires distributed.The analysis technique used in this research is descriptive statistics, multiple linear regression, classical assumption test, hypothesis testing ( $\mathrm{t}$ test). Data processing using statistical tools. The results of this study prove that knowledge of tax regulations partially has no effect on taxpayer compliance. However, the perception of the effectiveness of the taxation system has an effect on taxpayer compliance. Meanwhile, simultaneously knowledge of tax regulations, and perceptions of the effectiveness of the taxation system have an effect on taxpayer compliance in several celebrities in the city of Palembang.
\end{abstract}

Keywords : knowledge of tax regulations, perceptions of the effectiveness of the taxation system, taxpayer compliance.

\section{PENDAHULUAN}

Fenomena perkembangan teknologi informasi yang semakin pesat membuat meningkatnya penggunaan internet secara mendunia terutama Indonesia. Indonesia tergolong kategori Negara dengan jumlah pengakses internet terbanyak 4.388 milyar berdasarkan data yang bersumber dari Laporan Digital Indonsia per Januari tahun 2019 yang dikeluarkan oleh We Are Social dan bekerjasama dengan Hootsuite. Laporan ini menunjukkan bahwa pengguna media sosial aktif di Indonesia sebanyak 150 juta pengguna (naik 13\% atau sekitar 17 juta dari tahun 2018) dengan persentase platforms media sosial yang paling aktif yakni youtube
$88 \%$, Whatsapp 83\%,Facebook $81 \%$, dan instagram $80 \%$.

Meningkatnya pengguna Instagram untuk profil bisnis membuat adanya kemunculan sebuah profesi baru yang disebut dengan Selebriti Instagram (selebgram). Pendapatan yang diperoleh seorang selebgram menjadi perhatian Direktorat Jenderal Pajak sebab penghasilan dari selebgram ini berpotensi sebagai salah satu sumber pendapatan Negara yang disalurkan melalui adanya pemungutan pajak. Berikut didapati data selebgram dikota Palembang yang di himpun dari website resmi sociabuzz.com yang telah penulis rangkum pada tabel dibawah ini : 
Tabel 1. Daftar Selebgram dikota Palembang

\begin{tabular}{|c|l|l|c|}
\hline \multirow{2}{*}{ No } & \multicolumn{1}{|c|}{ Nama } & Jenis Konten & Pengikut \\
\hline 1 & Efrin Sanora & $\begin{array}{l}\text { Food \& Drink, Beauty Enthusiast, } \\
\text { Lifestyle }\end{array}$ & $109 \mathrm{k}$ \\
\hline 2 & Yunita Dwi Ananda & Lifestyle, Food \& Drink, Fashion & $49 \mathrm{k}$ \\
\hline 3 & Muhammad K. Taufik & Lifestyle, Travel (Vacation) & $30 \mathrm{k}$ \\
\hline 4 & $\begin{array}{l}\text { Juju Onyols - } \\
\text { Sikonyols }\end{array}$ & Humor \& Comedy, Lifestyle & $142 \mathrm{k}$ \\
\hline 5 & Anjani & $\begin{array}{l}\text { Lifestyle, Fashion, Beauty, Travel } \\
\text { (Vacation) }\end{array}$ & $16 \mathrm{k}$ \\
\hline 6 & Kanditha Rechta & $\begin{array}{l}\text { Parenting \& Family, Lifestyle, Beauty, } \\
\text { Fashion }\end{array}$ & $32 \mathrm{k}$ \\
\hline 7 & Deddy Huang & Photography, Travel (Vacation) & $12 \mathrm{k}$ \\
\hline 8 & Sindy Javita Sisilia & Beauty, Fashion, Lifestyle & $13 \mathrm{k}$ \\
\hline 9 & Ceri Seli Selika & Fashion, Lifestyle, Beauty & $20 \mathrm{k}$ \\
\hline 10 & Ratih Kirana Sari & Lifestyle, Tiktok & $14 \mathrm{k}$ \\
\hline 11 & Tata Redita & Beauty, Lifestyle & $49 \mathrm{k}$ \\
\hline 12 & Tria Kurnia Futri & Lifestyle & $13 \mathrm{k}$ \\
\hline 13 & Kalena Efris & Lifestyle, Travel (Adventure) & $11 \mathrm{k}$ \\
\hline 14 & Dea Dwi Maharani & Lifestyle, Food \& Drink, Fashion & $13 \mathrm{k}$ \\
\hline 15 & Ni'matul Hakiki & Lifestyle & $15 \mathrm{k}$ \\
\hline 16 & Dian Soediro & Lifestyle, Fashion, Beauty & $17 \mathrm{k}$ \\
\hline 17 & Sutrawati Yelly & Beauty, Lifestyle, Travel (Vacation) & $18 \mathrm{k}$ \\
\hline 18 & Syarah Tania & $\begin{array}{l}\text { Fashion, Lifestyle, Food \& Drink, Travel } \\
\text { (Vacation) }\end{array}$ & $83 \mathrm{k}$ \\
\hline 19 & Ananda Ayu Novella & Lifestyle, & $14 \mathrm{k}$ \\
\hline 20 & Dinda Dwi Lestari & Beauty, Lifestyle, Fashion & $19 \mathrm{k}$ \\
\hline 21 & Fadhilah Yulinda S & Lifestyle, Food \& Drink, Beauty, Fashion & $22 \mathrm{k}$ \\
\hline 22 & Andres Fareza & Travel (Vacation), Lifestyle, Fashion & $10 \mathrm{k}$ \\
\hline 23 & M.adjie Bayu Poetra & Lifestyle & $18 \mathrm{k}$ \\
\hline 24 & Resi Arsita & Lifestyle, Fashion & $10 \mathrm{k}$ \\
\hline 25 & Regina Veleria Putri & Lifestyle, Beauty, Travel (Vacation) & $17 \mathrm{k}$ \\
\hline 26 & Salsa Melania Aquina & Lifestyle & $17 \mathrm{k}$ \\
\hline 27 & Shinta Iriani Yasmine & Lifestyle, Travel (Vacation) & $24 \mathrm{k}$ \\
\hline 28 & Khuswatun Khasanah & Lifestyle & $15 \mathrm{k}$ \\
\hline 29 & Ando Ferrynico Tan & Tiktok, Fashion, Lifestyle & $10 \mathrm{k}$ \\
\hline 30 & Fjelsaa & Beauty, Fashion, Lifestyle \\
\hline 31 & Ardi Roque & Lifestyle, Fitness & $32 \mathrm{k}$ \\
\hline
\end{tabular}

Sumber : sociabuzz.com/selebgram/asal-palembang 
Kejujuran seorang selebgram untuk melaporkan penghasilan yang didapatkan dalam satu tahun berjalan perlu menjadi pengawasan khusus Direktorat Jenderal Pajak (selanjutnya disebut DJP). Pemerintah harus jelas menentukan selebgram dengan kategori apa yang dapat dikatakan sebagai selebgram, bagaimana bentuk pengawasan, bagaimana pengaturan sanksi apabila selebgram tidak melaporkan SPT tahunan, dan bagaimana dapat memprediksikan perkembangan selebgram dalam beberapa tahun mendatang. Terakhir pada bulan Januari 2019 DJP sedang mengembangkan sebuah sistem bernama social network analytics(SONETA) yang diharapkan dapat terintegrasi disemua media sosial dan mampu mengakomodir penyandingan data untuk pajak penghasilan (PPh).Namun, hingga saat ini semakin maraknya akun selebgram tetapi DJP belum menunjukkan hasil yang diharapkan.

\section{METODE PENELITIAN}

Penelitian dilakukan dengan menggunakan pendekatan asosiatif. Penelitian untuk mengetahui pengaruh hubungan antara variabel bebas dan variabel terikat. Variabel bebas adalah pengetahuan peraturan pajak, persepsi efektivitas sistem perpajakan.Variabel terikatnya adalah kepatuhan wajib pajak. Teknik pengambilan sampel menggunakan Purposive Sampling. Subjek penelitian diambil dengan melakukan pertimbangan kriteria tertentu yang telah ditentukan oleh peneliti, yaitu:

1) Pengguna instagram yang mengupload konten untuk menarik followers.

2) Minimal memiliki setidaknya 10.000 followers atau pengikut di media sosial instagram.

3) Berdomisili di kota Palembang.

Tabel 2.Operasional Variabel

\begin{tabular}{|c|c|c|c|c|}
\hline No & Variabel & Pengertian & Indikator & $\begin{array}{c}\text { Sumber } \\
\text { Data }\end{array}$ \\
\hline 1 & $\begin{array}{l}\text { Pengetahuan } \\
\text { Peraturan Pajak } \\
\text { (X1) }\end{array}$ & $\begin{array}{lr}\text { Pengetahuan } & \text { perpajakan } \\
\text { merupakan } & \text { informasi } \\
\text { pajak yang } & \text { dapat } \\
\text { digunakan } & \text { untuk } \\
\text { pengambilan keputusan } \\
\text { dan tindakan yang terkait } \\
\text { dengan } \\
\text { (Subekti, 2016). }\end{array}$ & $\begin{array}{ll}\text { - } & \text { Pengetahuan } \\
\text { terhadap } \\
\text { peraturan. } \\
\text { - } \\
\text { Pengetahuan } \\
\text { Manfaat Pajak }\end{array}$ & $\begin{array}{l}\text { Dari } \\
\text { jawaban } \\
\text { responden }\end{array}$ \\
\hline 2 & $\begin{array}{l}\text { Persepsi } \\
\text { Efektivitas } \\
\text { Sistem } \\
\text { Perpajakan (X2) }\end{array}$ & $\begin{array}{lr}\text { Sistem } & \text { perpajakan } \\
\text { merupakan } & \text { administrasi } \\
\text { perpajakan. } & \text { (Musgrave, } \\
2014: 19 \text { ) } & \end{array}$ & $\begin{array}{l}\text { - Kemudahan } \\
\text { - Manfaat } \\
\text { - Kelemahan }\end{array}$ & $\begin{array}{l}\text { Dari } \\
\text { jawaban } \\
\text { responden }\end{array}$ \\
\hline 3 & $\begin{array}{l}\text { Kepatuhan } \\
\text { Wajib Pajak (Y) }\end{array}$ & $\begin{array}{lr}\text { Kepatuhan } & \text { Wajib } \\
\text { Pajak dapat didefinisikan } \\
\text { sebagai suatu keadaan } \\
\text { dimana Wajib } \\
\text { Pajakmemenuhi semua } \\
\text { kewajiban perpajakan dan } \\
\text { melaksanakan hak }\end{array}$ & $\begin{array}{l}\text { 1. Kepatuhan Wajib } \\
\text { Pajak dalam } \\
\text { mendaftarkan diri } \\
\text { 2. Kepatuhan dalam } \\
\text { penghitungan dan } \\
\text { pembayaran } \\
\text { pajak terutang }\end{array}$ & $\begin{array}{l}\text { Dari } \\
\text { jawaban } \\
\text { responden }\end{array}$ \\
\hline
\end{tabular}




\begin{tabular}{|l|l|l|l|}
\hline & $\begin{array}{l}\text { perpajakannya. (Safri } \\
\text { Nurmantu dalam Siti } \\
\text { Kurnia Rahayu, 2010:138) }\end{array}$ & $\begin{array}{r}\text { 3. Kepatuhan untuk } \\
\text { melaporkan Surat } \\
\text { Pemberitahuan } \\
\text { (SPT) }\end{array}$ & \\
\hline
\end{tabular}

Sumber : data diolah 2021

\section{HASIL DAN PEMBAHASAN Uji Validitas}

Tabel 3.

Hasil Pengujian Validitas Variabel Pengetahuan Peraturan Pajak (X1)

\begin{tabular}{|l|l|l|l|}
\hline \multicolumn{1}{|c|}{ No pertanyaan } & \multicolumn{1}{c|}{ r hitung } & \multicolumn{1}{c|}{ r table } & Keterangan \\
\hline Pertanyaan 1 & 0,712 & 0,30 & Valid \\
\hline Pertanyaan 2 & 0,719 & 0,30 & Valid \\
\hline Pertanyaan 3 & 0,671 & 0,30 & Valid \\
\hline Pertanyaan 4 & 0,424 & 0,30 & Valid \\
\hline Pertanyaan 5 & 0,472 & 0,30 & Valid \\
\hline Pertanyaan 6 & 0,542 & 0,30 & Valid \\
\hline Pertanyaan 7 & 0,438 & 0,30 & Valid \\
\hline
\end{tabular}

Sumber : data diolah2021

Tabel 4.

Hasil Pengujian Validitas Variabel Persepsi Efektivitas Sistem Perpajakan (X2)

\begin{tabular}{|l|l|l|l|}
\hline No pertanyaan & r hitung & r table & Keterangan \\
\hline Pertanyaan 8 & 0,579 & 0,30 & Valid \\
\hline Pertanyaan 9 & 0,563 & 0,30 & Valid \\
\hline Pertanyaan 10 & 0,801 & 0,30 & Valid \\
\hline Pertanyaan 11 & 0,695 & 0,30 & Valid \\
\hline Pertanyaan 12 & 0,694 & 0,30 & Valid \\
\hline Pertanyaan 13 & 0,599 & 0,30 & Valid \\
\hline Pertanyaan 14 & 0,478 & 0,30 & Valid \\
\hline Pertanyaan 15 & 0,762 & 0,30 & Valid \\
\hline
\end{tabular}

Sumber : data diolah 2021

Tabel 5.

Hasil Pengujian Validitas Variabel Kepatuhan Wajib Pajak (Y)

\begin{tabular}{|l|l|l|l|}
\hline No pertanyaan & r hitung & r table & Keterangan \\
\hline Pertanyaan 16 & 0,686 & 0,30 & Valid \\
\hline Pertanyaan 17 & 0,660 & 0,30 & Valid \\
\hline Pertanyaan 18 & 0,711 & 0,30 & Valid \\
\hline Pertanyaan 19 & 0,493 & 0,30 & Valid \\
\hline Pertanyaan 20 & 0,554 & 0,30 & Valid \\
\hline Pertanyaan 21 & 0,379 & 0,30 & Valid \\
\hline Pertanyaan 22 & 0,559 & 0,30 & Valid \\
\hline
\end{tabular}




\begin{tabular}{|l|l|l|l|}
\hline Pertanyaan 23 & 0,824 & 0,30 & Valid \\
\hline Pertanyaan 24 & 0,683 & 0,30 & Valid \\
\hline Pertanyaan 25 & 0,505 & 0,30 & Valid \\
\hline
\end{tabular}

Sumber : data diolah 2021

Berdasarkan perhitungan korelasi product pearson dengan menggunakan analisis correlate bivariate, diketahui bahwa setiap item pernyataan dari variabel pengetahuan peraturan pajak (X1), variabel persepsi efektivitas sistem perpajakan (X2) dan variabel kepatuhan wajib pajak (Y) diperoleh nilai $r$ hitung lebih besar dari nilai $r$ tabel. Sehingga dapat disimpulkan bahwa seluruh butir pernyataan dari ketiga variabel valid dan dapat digunakan untuk dilakukan pengujian selanjutnya.

\section{Uji Reliabilitas}

Tabel 6.

Hasil Uji Reliabilitas

\begin{tabular}{|l|l|l|l|}
\hline Variabel & Cronbach's alpha & Ketentuan & Hasil \\
\hline Y & 0,812 & 0,05 & Reliabel \\
\hline X1 & 0,656 & 0,05 & Reliabel \\
\hline X2 & 0,805 & 0,05 & Reliabel \\
\hline
\end{tabular}

Sumber : data diolah 2021

Berdasarkan tabel 6 di atas hasil pengujian reliabilitas dari setiap pernyataan untuk variabel X1 nilai Cronbach's Alpha 0,656 (lebih dari 0,05), variabel X2 nilai Cronbach's Alpha 0,805 (lebih dari 0,05) dan variabel Y nilai Cronbach's Alpha 0,812 (lebih dari 0,05). Sehingga dapat disimpulkan semua variabel dinyatakan reliabel.

\section{Analisis Regresi Berganda}

Tabel 7.

\section{Hasil Pengujian Analisis Regresi Berganda}

Coefficients $^{\mathrm{a}}$

\begin{tabular}{|ll|l|l|l|l|l|}
\hline \multicolumn{2}{|l|}{ Model } & \multicolumn{2}{|l|}{ Unstandardized Coefficients } & $\begin{array}{l}\text { Standardized } \\
\text { Coefficients }\end{array}$ & $\mathrm{t}$ & \multirow{2}{*}{ Sig. } \\
\cline { 2 - 5 } & $\mathrm{B}$ & Std. Error & Beta & \\
\hline & (Constant) & 16.407 & 5.937 & & 2.764 & .010 \\
1 & $\mathrm{X} 1$ & -.166 & .230 & -.117 & -.724 & .475 \\
& $\mathrm{X} 2$ & .852 & .197 & .701 & 4.323 & .000 \\
\hline
\end{tabular}

a. Dependent Variable: $Y$

Sumber : data diolah 2021

Berdasarkan tabel 7 coefficients, persamaan regresi linear berganda yaitu:

Keterangan:

$$
Y: 16,407-0,166 X_{1}+0,852 X_{2}
$$


E : Tingkat Error, Tingkat Kesalahan

Nilai $\mathrm{a}=16.407$ Tanpa adanya responden yang memiliki pengetahuan peraturan pajak, persepsi efektivitas sistem perpajakan, kepatuhan wajib pajak akan tetap sama yaitu 16.407 .

1. Nilai koefisien X1 sebesar $-0,166$ artinya apabila terdapat penurunan variabel pengetahuan peraturan pajak sebesar 1 satuan sementara variabel independen lainnya tetap, kepatuhan wajib pajak (Y) akan mengalami penurunan $-0,166$.

2. Nilai koefisien $X 2$ sebesar 0,852 artinya apabila terdapat peningkatan variabel persepsi efektivitas sistem perpajakan sebesar 1 satuan sementara variabel independen lainnya tetap, kepatuhan wajib pajak (Y) akan mengalami peningkatan sebesar 0,852 .

\section{Uji Parsial (Uji t)}

Berdasarkan

tabel7pengujian hipotesis dengan menggunakan uji t, diketahui bahwa nilai t hitung pada variabel pengetahuan peraturan pajak lebih kecil dari $\mathrm{t}$ tabel $[\mathrm{n}-\mathrm{k}-1],(-, 724<2,048)$. Hipotesis dari Hal ditolak. Membuktikan bahwa tidak terdapat pengaruh terhadap kepatuhan wajib pajak. Probabilitasnya (sig), menjelaskan bahwa 0,475>0,05, Ha1 ditolak.

Pengujian hipotesis untuk variabel persepsi efektivitas sistem perpajakan diperoleh $\mathrm{t}$ hitung sebesar 4,323. $\mathrm{t}$ tabel dari variabel ini adalah $[\mathrm{n}-\mathrm{k}-1],(4,323<$ 2,048) Ha2 diterima.Terdapat pengaruh terhadap kepatuhan wajib pajak. Probabilitasnya (sig), menjelaskan bahwa $0,000>0,05, \mathrm{Ha} 2$ diterima. $\mathrm{Ha} 2$ ini menunjukkan bahwa variabel persepsi efektivitas sistem perpajakan berpengaruh secara signifikan terhadap kepatuhan wajib pajak.

\section{Uji Simultan (Uji F)}

Tabel 8.Hasil Pengujian Simultan (Uji F)

ANOVA $^{\mathrm{a}}$

\begin{tabular}{|ll|r|r|r|r|r|}
\hline Model & & Sum of Squares & Df & Mean Square & F & \multicolumn{1}{c|}{ Sig. } \\
\hline 1 & Regression & 320,343 & 2 & 160,172 & 10,446 &, $000^{\mathrm{b}}$ \\
\cline { 2 - 7 } & Residual & 429,334 & 28 & 15,333 & & \\
\hline & Total & 749,677 & 30 & & & \\
\hline
\end{tabular}

a. Dependent Variable: $Y$

b. Predictors: (Constant), X2, X1

Sumber : data diolah 2021

Berdasarkan hasil uji hipotesis nilai F hitung sebesar 10,446.Nilai F untuk tarif nayta $\alpha$ $5 \%$ adalah 30. Nilai $t$ hitung 10,446> F tabel 3,34. Berdasarkan hasil uji $\mathrm{F}$ ini juga dapat diketahui bahwa nilai signifikansi (sig) adalah 0,000 yang berarti bahwa sig $(0,000<\alpha)$. Menunjukkan terdapat signifikansi yang kuat terjadi pada variabel bebas terhadap variabel terikat. 


\section{Uji Koefisien Determinasi}

Tabel 9.Hasil Pengujian Koefisien Determinasi

\begin{tabular}{|c|c|c|c|c|}
\hline \multicolumn{5}{|c|}{ Model Summary ${ }^{b}$} \\
\hline Model & $\mathrm{R}$ & R Square & Adjusted R Square & Std. Error of the Estimate \\
\hline 1 & $654^{\mathrm{a}}$ & ,427 & ,386 & 3,916 \\
\hline
\end{tabular}

Sumber : data diolah 2021

Nilai koefisen determinasi R Square sebesar $0,427.42,7 \%$ variasi variabel dapat dijelaskan oleh kepatuhan wajib pajak dan $57,3 \%$ dijelaskan oleh variabel lain yang tidak diteliti dalam penelitian ini.

\section{Pembahasan}

Pada variabel pengetahuan peraturan pajak yang dimiliki dari latar belakang pendidikan, dari informasi yang sangat mudah didapat tentang peraturan pajak, cara mengisi SPT yang sangat mudah, dan informasi tentang cara penghitungan besaran pajak yang harus disetorkan kepada Pemerintah melalui Direktorak Jenderal Pajak ( DJP ), tidak menjamin bahwa wajib pajak akan lebih patuh dalam melaksanakan kewajiban perpajakannya. Diharapkan Pemerintah atau petugas pajak memberikan kegiatan yang dapat memberikan pengetahuan terkait perpajakan kepada wajib pajak baik melalui sosialisasi atau membuat suatu acara yang menarik untuk anak muda supaya pemahaman peraturan pajak dapat masuk ke kalangan anak muda dan menjadi perbincangan diperkumpulan anak muda yang pada akhirnya akan meningkatkan kepatuhan wajib pajak.Kondisi ini sejalan dengan penelitian yang dilakukan oleh fita et al (2018),yang berpendapat bahwa pengetahuan perpajakan yang dimiliki dari latar belakang pendidikan wajib pajak tidak menjamin bahwa wajib pajak akan lebih patuh dalam melaksanakan kewajiban perpajakan.

Pengujian hipotesis untuk variabel persepsi efektivitas sistem perpajakan menunjukkan $\mathrm{Ha} 2$ diterima.Efektivitas sistem perpajakan yang dirasakanoleh wajib pajak orang pribadi (seorang selebgram) berpengaruh terhadap kepatuhan wajib pajak dengan signifikan. Wajib pajak untuk menjadi patuh harus memiliki Nomor Pokok Wajib Pajak ( NPWP ). Wajib pajak sudah bisa mendapatkan atau mendaftarkan diri untuk bisa memiliki NPWP dimanapun mereka berada asalkan memiliki gadged seperti smartphone, laptop, atau $P C$ dan koneksi internet. Begitu juga dengan metode pembayaran yang dapat dilakukan melalui $e$ banking, dan pelaporan melalui e-filling semua sudah dapat dilakukan dimanapun dan kapanpun, menjadikan wajib pajak semakin patuh terhadap kepatuhan perpajakan.Kondisi ini sejalan dengan penelitian Nugroho (2012), yaitu sistem perpajakan yang ada sekarang lebih efektif dan lebih memudahkan wajib pajak dalam memenuhi kewajiban perpajakan dan akan meningkat pula kemauan wajib pajak untuk membayar pajak.

Dengan memperhatikan hasil penelitian terutama pada pembahasan uji simultan (uji f) telah menunjukkan bahwa variabel pengetahuan peraturan pajak danpersepsi efektivitas sistem perpajakan memiliki pengaruh terhadap kepatuhan wajib pajak secara simultan. Ditunjukkan dengan 
nilai $\mathrm{F}$ hitung pada tabel anova lebih besar dari $F$ tabel $[\mathrm{n}-\mathrm{k}-1],(10,446>3,34)$ atau juga dapat dilihat dari nilai (Sig.) yang lebih kecil dari 0,05 $(0,000<0,05)$.

Kemampuan variabel independen dalam menjelaskan variabel dependendalam penelitian ini sebesar $42,7 \%$ dan $57,3 \%$ dijelaskan oleh variabel lain yang tidak diteliti dalam penelitian ini.

\section{KESIMPULAN}

1. Variabel pengetahuan peraturan pajak tidak berpengaruh terhadap kepatuhan wajib pajak, karena seorang wajib pajak yang kali ini ialah selebgram dikota Palembang mengetahui atau tidaknya dengan peraturan pajak yang sudah berlaku tidak menjamin bahwa wajib pajak akan lebih patuh terhadap kewajiban perpajakan.

2. Variabel persepsi efektivitas sistem perpajakan berpengaruh secara signifikan terhadap kepatuhan wajib pajak, karena seorang wajib pajak yang kali ini ialah selebgram dikota Palembang merasakan langsung manfaat dari perkembangan sistem perpajakan yang sudah ada.

\section{Daftar Pustaka}

Ajzen, I. (1985). From Intentions to $\mathrm{Be}$ havior: A Theory o f Planned Behavior. In J. Kuhl dan J. Beckman (Eds.): 11-39.

Andriani, P.J.A. 2005. Pengantar Ilmu Hukum Pajak. Jakarta: Salemba Empat.

Aristanti Widiyanigsih.2011. Hukum Pajak dan perpajakan dengan pendekatan Mind Map, cetakan Pertama, Bandung: CV Alfabeta.

Atmoko Dwi, Bambang. 2012. Instagram Handbook Tips Fotografi Ponsel. Jakarta: Media Kita.

Anwar Sanusi. 2012. Metode Penelitian Bisnis. Jakarta: PT. Salemba Empat.
Bambang, Riyanto. 2012. Dasar-dasar Pembelanjaan, Edisi 4, Yogyakarta: BPFE.

Djajadiningrat. 2011. Perpajakan Indonesia, Jakarta: Salemba Empat.

Fahluzy, F. M., Agustina L. 2014. "FaktorFaktor Yang Mempengaruhi Kepatuhan Membayar Pajak Umum Di Kabupaten Kendal". Accounting Analysis Journal. Jurusan Akuntansi Fakultas Ekonomi dan Bisnis Universitas Negeri Semarang.

Fishbein, M, \& Ajzen, I. (1975). Belief, Attitude, Intention, and Behavior: An Introduction to Theory and Research, Reading, MA: Addison-Wesley.

Hardiningsih, Pancawati dan Nila Yulianawati. 2011. Faktor-Faktor Yang Mempengaruhi Kemauan Membayar Pajak. Dinamika Keuangan dan Perbankan. Vol. 3, No. 1. Hal. 126 - 142.

Janie, Dyah Nirmala Arum. (2012). Statistik Deskriptif \& Regresi Linear Berganda Dengan SPSS. Semarang : Semarang University Press.

Mardiasmo. 2011. "Perpajakan Edisi Revisi”. Yogyakarta: Andi.

Peraturan Direktur Jenderal Pajak Nomor PER-32/PJ/2015 Tentang Pedoman Teknis Tata Cara Pemotongan, Penyetoran dan Pelaporan Pajak Penghasilan Pasal 21 ayat 1.

Peraturan Direktur Jendral Pajak Nomor PER-16/PJ/2016 tentang Pedoman Teknis Tata Cara Pemotongan, Penyetoran dan Pelaporan Pajak Penghasilan Pasal 21 dan/atau Pajak Penghasilan Pasal 26 Sehubungan dengan Pekerjaan, Jasa dan Kegiatan Orang Pribadi.

Peraturan Menteri Keuangan No 101/PMK.010/2016 tentang Penyesuaian Besarnya Penghasilan Tidak Kena Pajak. 
Ramadiansyah, Dimas, dkk. 2014. "Analisis Faktor-Faktor yang Mempengaruhi Wajib Pajak Orang Pribadi dalam Memenuhi Kewajiban Membayar Pajak (Studi Kasus pada Kantor Pelayanan Pajak Pratama Singosari)".

Resmi, Siti, (2013), Perpajakan: Teori dan Kasus, Edisi 7, Salemba Empat, Jakarta.

Republik Indonesia. 2015. Peraturan Direktur Jenderal Pajak Nomor PER17/PJ/2015 tentang Norma Penghitungan Penghasilan Neto.
Direktur Jenderal Pajak Republik Indonesia. Jakarta.

sociabuzz.com/selebgram/asal-palembang. Sugiyono. 2012. Metode Penelitian Kuantitatif Kualitatif dan R\&B. Bandung: Alfabeta.

Undang-Undang Republik Indonesia Nomor 28 Tahun 2007 tentang Perubahan Ketiga atas Undang-Undang Nomor 6 Tahun 1983 tentang Ketentuan Umum dan Tatacara Perpajakan (KUP).

Waluyo. (2014). Perpajakan Indonesia. Jakarta: Salemba Empat 